\title{
O eco de fantasmas: perpetuação da misoginia no cânone
}

The Echo of Ghosts: Misogyny Perpetuation in the Canon

Thalita da Silva Coelho

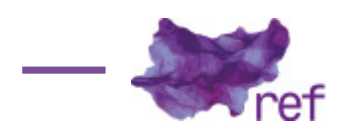

ANTUNES, Luísa Marinho.

As malícias das mulheres: discursos sobre poderes e artes das mulheres na cultura portuguesa e europeia.

Lisboa: Esfera do Caos, 2014. 236 p.

Pandora, a primeira mulher, criada por Zeus com o objetivo de trazer ao mundo o equilíbrio entre bem e mal, é a figura contrária ao homem: por trás da aparência bela e virginal, reside o mal que é capaz de descumprir uma ordem divina de jamais abrir a caixa que continha as desgraças do mundo - caixa esta que pode facilmente ser entendida como uma metáfora para o órgão sexual feminino. A ideia de que as mulheres se aproveitam de sua beleza e sensualidade para seduzir e manipular homens e de que são astuciosas e inteligentes - mas sempre para atividades nefastas - mesmo que consideradas inferiores ao seu oposto, aparece nos textos de Hesíodo, será herdada pela tradição judaico-cristã e, consequentemente, repetida no mundo com a força de uma verdade absoluta, principalmente por conta do domínio da Igreja Católica sob o ocidente.

Nas raízes do catolicismo estão crenças greco-romanas e judaicas, as primeiras, como nos conta Michel Foucault (1998), eram baseadas na moral aristotélica que afirmava caber ao homem o papel de mandar e à mulher, o de obedecer. Esta máxima valia também no campo sexual: quem deveria dominar era a figura masculina e também era de sua responsabilidade a saúde do órgão sexual feminino, pois era a penetração e absorção do esperma que garantiria à mulher o orgasmo e um corpo saudável: "A penetração pelo homem e a absorção do esperma são para o corpo da mulher o princípio do equilíbrio de suas qualidades e a chave para o escoamento necessário de seus humores." (FOUCAULT, 1998, p. 116).

Para o judaísmo não era muito diferente: suas bases eram patriarcais e à mulher cabia gerar, amamentar e cuidar dos filhos. Sobre a figura de Deus está sustentado um modelo de dominação que se tornará hegemônico, como diz Ivone Gebara (1991) sobre a tradição judaica:

De vez em quando alguém destoava do grupo e passava a chamar Deus de mãe, de Terramãe, de sabedoria infinita, de Mistério da Vida. Mas todos esses nomes e 'jeitos' diferentes de chamar Deus não eram muito freqüentes. Isso porque toda a organização política, social e religiosa desse povo repousava sobre os pais-chefes e, portanto, Deus tinha que continuar sendo $\circ$ Grande Pai para que se pudesse manter a estabilidade social e religiosa do grupo. (GEBARA, 1991, p. 35 apud Rita de LIMA, 2010, p. 2).

Se a figura de Deus era a masculina, ser mulher se distanciava do divino. Nesse sentido, para Rita de Lima $(2010$, p. 3), 
Qualquer mulher só pode se identificar com o Deus-Pai hebraico através da negação de sua própria identidade. Ser mulher passou a significar estar mais propensa ao mal, mais suscetível às ciladas do demônio. É neste contexto de sociedade patriarcal que se insere, portanto, a narrativa judaica da criação da mulher depois do homem e a partir dele (da costela), e o mito judaico do pecado original, no qual a mulher se torna responsável pelo pecado e sofrimento da humanidade.

Este processo de citação e rememoração de crenças, concretizado na lgreja Católica e no seu domínio sobre o ocidente a partir do século IV, é um exemplo do que encontramos no livro As malícias das mulheres - discursos sobre poderes e artes das mulheres na cultura portuguesa e europeia, em que Luísa Marinho Antunes, Doutora em Literatura Comparada pela Universidade de Madeira, realiza uma trajetória a partir de textos religiosos, literários, filosóficos, jurídicos e científicos, apontando historicamente a construção e enraizamento da misoginia. Apesar de uma análise eurocentrada, à medida que adentramos às linhas de Luísa, percebe-se um olhar cuidadoso para as partes que compõem aquilo que é cânone e, portanto, é citado na maioria da literatura contemporânea. Esse desmembramento dos modelos universais é necessário para compreender o poder da literatura canônica, já que propaga, dentre tantas discussões pertinentes, uma boa dose de misoginia, como é possível notar no discurso de Platão: segundo o autor de Registro $Y$ Estado, o filósofo grego "dava graças a Deus de três coisas: ser grego e não bárbaro, ter nascido homem e não animal, ser homem e não mulher" (Luísa Marinho ANTUNES, 2014, p. 22). Durante a leitura da obra de Luísa Marinho Antunes (2014), como bem aponta a autora, percebemos que discursos distintos, praticamente compostos por vozes masculinas, convergem para construir um imagético sobre a figura da mulher.

A obra de Antunes é dividida em três grandes capítulos, cada qual com suas subdivisões: "Obras, autores, diálogos, tratados e disputas nas malícias femininas"; "Faladoras, enganadoras, infiéis, traidoras, falsas e pecadoras: topoi mais característicos" e "O confronto português entre os sexos: reciprocidade nas acusações". Além dos três eixos principais de discussão, o livro ainda apresenta uma parte considerável de excertos literários datados de 1738 a 1805 e uma bibliografia para quem se interessar em estudar os textos de malícias ou os textos de defesa das mulheres.

Na primeira parte, "Obras, autores, diálogos, tratados e disputas nas malícias femininas", dá-se conta do panorama geral sobre os discursos referente à malícia das mulheres, analisando pontos que se destacam na história, como a estética medieval, os topoi da figura feminina e a evolução científica dos séculos XIX e XX. Inicia-se o panorama pela cultura greco-latina, passando pela Idade Média, inclusive pela figura da mulher diabólica, a bruxa, delineada em detalhes no Malleus Maleficarum, o manual de caça às bruxas na Inquisição.

"Faladoras, enganadoras, infiéis, traidoras, falsas e pecadoras: topoi mais característicos", a segunda parte do livro, aborda a tradição portuguesa dos textos das malícias, em sua grande maioria publicado em folhetos; é também nessa seção que Luísa Marinho Antunes apresenta os topoi, estereótipos femininos perpetuados através dos discursos canônicos.

Por último, "O confronto português entre os sexos: reciprocidade nas acusações", a terceira parte do livro, traz a resposta das mulheres às acusações de malícia, provenientes de textos datados dos séculos XVIII a início do XX. Nesse momento, prova-se que as mulheres, agora com a possibilidade de se pronunciarem, revoltam-se e defendem-se, muitas vezes utilizando a acusação aos homens como arma. Luísa analisa os argumentos utilizados dos dois lados, em respostas e contra-respostas.

Como excerto do livro estão disponíveis para leitura diversos textos que a autora cita no decorrer de seu discurso, tanto aqueles que trazem a malícia das mulheres quanto textos de defesa, entre os quais se encontra o discurso de resposta que duas mulheres portuguesas fazem a um texto de um brasileiro em 1789.

Ao longo dos capítulos, As malícias das mulheres... lembra o movimento feito por Thomas Laqueur em Inventando o sexo: corpo e gênero dos Gregos a Freud (2001). Nesse livro, o historiador e sexólogo faz um panorama histórico de diferentes concepções sociais e científicas acerca de sexo e gênero, o que nos possibilita observar que nem sempre as visões sobre sexo biológico e gênero acompanharam descobertas científicas e da medicina, mas estavam muito mais condicionadas aos contextos sociais de seu meio. Novamente, as construções sócio-históricas imbricam-se para dar base ao que será perpetuado e repetido século após século.

Luísa utiliza a ideia de topoi, advinda da dialética de Aristóteles: um senso comum utilizado como ponto de partida para a argumentação. Para a autora, as mulheres foram representadas a partir de dois estereótipos desde os gregos antigos: a mulher santa e a mulher demônio. A primeira é uma figura materna, cuidadosa, submissa, que nos lembra muito a Virgem Maria; a segunda é maliciosa, sexual, ardilosa, características associadas a Eva. Os dois exemplos dados são da tradição cristã, mas os exemplos de mulheres que se encaixam nesses topoi são muitos e aparecem, inclusive, na mitologia greco-latina, que muitas vezes teve sua essência absorvida pela Igreja Católica: Penélope é a mulher pura, honesta e fiel que espera o retorno do marido ao lar; Helena de Troia, a mulher mais linda do mundo, é apontada como a causa da ruína da cidade. Desde a 
Antiga Grécia até a contemporaneidade, o pensamento masculinista não vê meio termo, as mulheres sempre ocuparam estes dois modelos maniqueístas. Acontece que a própria existência desses dois estereótipos nos diz muito mais sobre os receios dos homens em relação às mulheres do que sobre a mulher especificamente: a tentativa de condicionar o espaço feminino a dois tipos de personalidade, uma submissa, a outra maléfica, a primeira deve sempre ser resiliente, a segunda torna-se inimiga da bondade, consequentemente inimiga do homem, feito a imagem de Deus. Nenhum dos dois lugares permite a mulher ser melhor do que o homem, permanece sempre observando a tudo de baixo.

Se na Idade Média toda a sociedade é explicada a partir de Deus, no Renascimento há uma guinada em direção à Ciência e um rompimento com ideias puramente religiosas. Embora isso pareça significar imparcialidade e fim de preconceitos, sabemos que o saber científico não advém do nada, mas nasce impregnado pela lógica social e, por conseguinte, teológica. Laqueur (2001) destrincha os conceitos científicos sobre sexo e percebe como ciência, mitologia e religiosidade se misturam na biologia com o modelo do sexo único, vigente no período prélluminista:

O modelo do sexo único seria de um mundo onde pelo menos dois gêneros correspondem a apenas um sexo, onde as fronteiras entre masculino e feminino são de grau e não de espécie, e onde os órgãos reprodutivos são apenas um sinal entre muitos do lugar do corpo em uma ordem cósmica e cultural que transcende a biologia (LAQUEUR, 2001, p. 41).

A partir da premissa de que as categorias homem e mulher surgiram do social com a intenção de definir relações de poder e de que o saber científico muitas vezes esteve a serviço da manutenção do poder masculino, é possível analisar a propagação das ideias misóginas tanto nos exemplos trazidos por Luísa Marinho Antunes (2014) quanto no livro de Thomas Laqueur (2001), em especial quando observamos que o modelo do sexo único só foi substituído pelo dimorfismo sexual no século XVIII, quando o determinismo biológico passou a ser a justificativa incontestável para a existência de diferenças culturais e sociais.

Se ciência, teologia e cultura se fundem e ditam regras, sustentando um modelo patriarcal e patrilinear, o fenômeno que torna capaz tal acontecimento é a memória intertextual, ou seja, a informação repetida construindo a memória coletiva, sendo este um dos pontos mais importantes do livro de Luísa Marinho Antunes. A autora define a memória intertextual, resumidamente, como o reverberar de textos através da história, e não só dos textos, mas de seus conceitos e informações que, sabemos, estão condicionados a um contexto sócio-histórico e político.

Nas linhas do livro de Antunes, percebemos: a construção de um cânone baseando-se em regras sociais hierárquicas, e este cânone será repetido e repetido, ano após ano, século após século e seu resultado será uma voz hegemônica que nada mais é do que o eco de fantasmas. É este conceito que nos proporciona a repetição de autores canônicos e de suas vozes. O discurso é construído a partir de uma intertextualidade, inclusive aquele que segrega e perpetua o status quo, criando raízes na história e ganhando espaço como modelo a ser seguido. A partir do entendimento dessas entrelinhas e das origens de sistemas hierárquicos é que ganhamos força no embate para extinguir estruturas de opressão.

\section{Referências}

ANTUNES, Luísa Marinho. As malícias das mulheres: discursos sobre poderes e artes das mulheres na cultura portuguesa e europeia. Lisboa: Esfera do Caos, 2014.

FOUCAULT, Michel. História da Sexualidade 2: o uso dos prazeres. Trad. de Maria Thereza da Costa Albuquerque. Rio de Janeiro: Graal, 1998.

LAQUEUR, Thomas. Inventando o Sexo: Corpo e gênero dos gregos a Freud. Trad. de Vera Wathely. Rio de Janeiro: Relume Dumará, 2001.

LIMA, Rita de Lourdes de. "O imaginário judaico-cristão e a submissão das mulheres". In: FAZENDO GÊNERO, 9, 2010, Florianópolis. Anais.... Florianópolis: 2010. p. 1-9. Disponível em: http:// www.fazendogenero.ufsc.br/9/resources/anais/1277853385_ARQUIVO_comunicoraltrabcompleto Genero.pdf. Acesso em: 25/03/2018.

Thalita da Silva Coelho (iD) 0000-0003-4091-8062

Doutoranda em Teoria Literária (linha de pesquisa Crítica Feminista e Estudos de Gênero)

É vinculada ao nuLIME (núcleo Literatura e Memória). Recentemente, publicou o livro de poesia lésbico e feminista Terra molhada (Editora Patuá, 2018).

Universidade Federal de Santa Catarina, Programa de Pós-graduação em Literatura

R. Eng. Agronômico Andrei Cristian Ferreira, s/n, Trindade 
Florianópolis - SC - Brasil

(48) 3721-9000 - ppglitufsc@gmail.com

thalitasilvacoelho@gmail.com

\section{COMO CITAR ESSE ARTIGO DE ACORDO COM AS NORMAS DA REVISTA}

COELHO, Thalita da Silva. "O eco de fantasmas: perpetuação da misoginia no cânone". Revista Estudos Feministas, Florianópolis, v. 27, n. 1, e56309, 2019.

\section{CONTRIBUIÇÃO DE AUTORIA}

Não se aplica

FINANCIAMENTO

CNPq

CONSENTIMENTO DE USO DE IMAGEM

Não se aplica

APROVAÇÃO DE COMITÊ DE ÉTICA EM PESQUISA

Não se aplica

CONFLITO DE INTERESSES

Não se aplica

LICENÇA DE USO

Este artigo está licenciado sob a Licença Creative Commons CC-BY. Com essa licença você pode compartilhar, adaptar, criar para qualquer fim, desde que atribua a autoria da obra.

\section{HISTÓRICO}

Recebido em 10/04/2018

Aceito em 30/06/2018

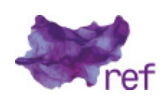

